American Journal of Pharmaceutical Education 2021; 85 (5) Article 8269.

\title{
QUALITATIVE RESEARCH
}

\section{A Teamwork Workshop to Improve Pharmacy Students' Growth Mindset and Communication Skills}

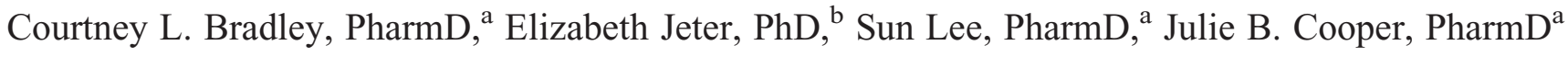 \\ ${ }^{\text {a }}$ High Point University, Fred Wilson School of Pharmacy, High Point, North Carolina \\ ${ }^{\mathrm{b}}$ High Point University, College of Arts and Sciences, High Point, North Carolina \\ Submitted July 2, 2020; accepted January 29, 2021; published May 2021.
}

\begin{abstract}
Objective. To determine the impact of a workshop on the growth mindset and team communication of first year Doctor of Pharmacy (PharmD) students.

Methods. A multi-week workshop was developed for first year pharmacy students. The workshop included completion of the StrengthsFinder 2.0, a session on identifying individual and team member strengths, a session on situational communication and conflict resolution models, and a work-up of two pharmacy scenarios requiring conflict resolution. The workshop was delivered to two intervention groups (fall 2019 and fall 2018) and compared to a control group (fall 2017). A pre-post survey was administered to measure change in students' growth mindset and team communication using the validated Growth Mindset and Team Communication (GMTC) tool. Data were analyzed using descriptive statistics, independent sample t tests, and chi-square tests to compare difference and association. Focus groups were conducted in fall 2017 and fall 2018 to assess students' views regarding teamwork.

Results. Team communication subscale scores increased significantly among students in the intervention group while there was no significant change in these scores among students in the control group. The focus groups reflected that students had overall positive views about team communication and collaboration, which were also supported by discussions of advantages and challenges during teamwork.

Conclusion. A teamwork workshop affected pharmacy students' communication skills. Future work should focus on longitudinal measurement of students' self-views to determine the long-term impact of teamwork training interventions.
\end{abstract}

Keywords: growth mindset, StrengthsFinder, teamwork, workshop, interpersonal skills

\section{INTRODUCTION}

Multidisciplinary health care teams are a complex social network that require collaboration and communication among the professionals that comprise the team in order to deliver effective and safe patient care. ${ }^{1}$ Because ineffective collaboration can lead to errors and poor patient outcomes, teamwork among health care professionals is essential for successful high-quality care. ${ }^{2}$ Doctor of Pharmacy (PharmD) graduates are expected to be teamready clinicians with the Accreditation Council for Pharmacy Education Standards 2016 calling for pharmacy students to participate in team-based interprofessional learning experiences. ${ }^{3}$ Implementation of interprofessional education (IPE) in the first year of the PharmD program is an important phase in the preparation of

Corresponding Author: Courtney L. Bradley, High Point University, Fred Wilson School of Pharmacy, One University Pkwy., High Point, NC 27268. Tel: 336-841-9715. Email: cbradley@highpoint.edu team-ready professionals. ${ }^{4}$ A typical element of IPE is teaching students about the roles of other health care professionals through interprofessional student teams. However, outcomes from this type of early intervention are mixed. ${ }^{5,6}$ Placing students together on a team may not necessarily result in the students aquiring improved teamwork skills. One possible explanation may be limited formal training for students on how to be a team member and how to develop interpersonal skills. This hypothesis is supported by surveys suggesting that new health professional graduates lack specific teamwork skills such as communication, conflict management, and team functioning. ${ }^{7}$

A common pedagogy used to teach teamwork in pharmacy education is having students work in groups for projects and team-based learning. Peer evaluation and peer feedback are often presented as reflective opportunities in which students can develop teamwork skills. ${ }^{8}$ However, in our experience, peer feedback is of limited value without a significant amount of explicit coaching and debriefing from faculty. Additionally, unresolved 


\section{American Journal of Pharmaceutical Education 2021; 85 (5) Article 8269.}

conflict between students can result in some students providing unexpected feedback to their peers well after the optimum time for coaching them regarding teamwork skills has passed. Furthermore, to make a lasting impact, students must then translate what they learned from these educational experiences during school to their future work on patient care teams.

In managing teamwork in the classroom, some students hold persistent beliefs that they must be on a "good" team to succeed or that they lack any control over their team's effectiveness. The belief that "I must be on a good team to succeed" is defined by Dweck as a fixed self-view or fixed mindset. ${ }^{9}$ A fixed mindset is the belief that a person's abilities and skills are unchangeable. Research suggests that fixed self-views undermine growth in the face of conflict. ${ }^{10}$ In contrast, learners with a growth mindset believe ability is not limited. Thriving team members may believe that "with hard work, I can succeed on any team." Growth mindset learners seek challenges and remain effective during conflict. ${ }^{11}$ Previous research involving PharmD students has demonstrated that a growth mindset is associated with the student having a favorable view of team learning. ${ }^{12}$ However, changes in growth mindset over time and in the setting of team conflict lack study. Investigation into the relationship between students' beliefs and growth on teams is needed to provide guidance for development of teamwork pedagogies.

Focused education on teamwork and conflict management delivered to students early in the pharmacy curriculum may impact team readiness. From this hypothesis, we developed a process-based approach to interpersonal relationships in the form of a pre-IPE intervention for first professional year (PY1) pharmacy students. We used a continuous professional development
(CPD) framework for the teamwork workshop that emphasized personalized learning strategies to encourage lifelong learning. ${ }^{13}$ The StrengthsFinder survey was selected as a basis for individualization because of preliminary work done with pharmacy students using this tool. ${ }^{14,15}$ StrengthsFinder allowed students a lens to understand their individual strengths that they have within themselves so that can use this personal information as a base going into teamwork. The goal is for students to understand their strengths so that they know what they can bring to a team. Growth mindset was promoted through situational teamwork training as trait identification alone may reinforce fixed mindsets. The learning goal of the teamwork workshop was to equip pharmacy students early with the fundamental interpersonal skills needed for conflict resolution. The objective of this study was to develop, implement, and assess the impact of a teamwork workshop on growth mindset and team communication using the validated Growth Mindset and Team Communication (GMTC) tool. ${ }^{16}$

\section{METHODS}

A multi-week workshop (five contact hours) for pharmacy students was created and incorporated into a required fall semester PY1 lecture course (Introduction to Pharmacy Practice) and laboratory course (Clinical Skills Lab I). An overview of the workshop's timeline is provided in Figure 1. The multi-week series began during orientation with students learning about their personal traits by completing the StrengthsFinder 2.0 self-evaluation. ${ }^{15}$ During week 1 of the semester, the course coordinator collected the students' results from the StrengthsFinder 2.0 in an Excel spreadsheet and used the stratified sampling allocation technique to

\begin{tabular}{|c|c|}
\hline Orientation & - StrengthsFinder assessment completed by each student. \\
\hline Week 1 & $\begin{array}{l}\text { - Pre-survey } \\
\text { - Use of pre-survey results to create diverse student groups }\end{array}$ \\
\hline Week 3 & - Classroom lecture on recognizing individual and team members' strengths ( $\sim 80$ minutes) \\
\hline Week 4 & $\begin{array}{l}\text { - Laboratory session where groups completed two pharmacy scenarios by identifying characters' primary } \\
\text { strengths and workplace needs ( } \sim 60 \text { minutes) }\end{array}$ \\
\hline Week 7 & $\begin{array}{l}\text { - Classroom lecture on process-oriented communication models and situational communication and group } \\
\text { conflict resolution tools ( } \sim 80 \text { minutes) }\end{array}$ \\
\hline Week 8 & $\begin{array}{l}\text { - Laboratory session identifying conflict process elements, contributing factors, workplace needs, and } \\
\text { development of a conflict management note and narrative. ( } \sim 60 \text { minutes) }\end{array}$ \\
\hline Week 9 & $\begin{array}{l}\text { - Laboratory session where groups acted out their narrative. This was followed by a short debriefing session } \\
\text { conducted by the faculty facilitator ( } \sim 30 \text { minutes) }\end{array}$ \\
\hline Week 15 & - Post-Survey \\
\hline
\end{tabular}

Figure 1. Outline of Multi-week Teamwork and Conflict Management Workshop Components. Timeline Provided for Lecture and Laboratory Sessions Along with Pre- and Post-survey Administration. 


\section{American Journal of Pharmaceutical Education 2021; 85 (5) Article 8269.}

divide students into groups which were maintained for all planned course activities. Heterogeneous groups were created by balancing students' strengths according to the four StrengthsFinder domains ${ }^{15}$ as well as by taking into account their pharmacy work experience, educational experience, and student self-identification of certain traits, such as tendency towards being an introvert or extrovert.

During week 3 of the semester, the workshop continued with a classroom session on recognizing individual and team members' strengths. This 80 -minute interactive session focused on understanding personal strengths, professional teamwork relationships, and workplace needs and was led by a pharmacist. During week 4, students applied these concepts in the laboratory course where groups worked through two pharmacy team scenarios with a focus on diverse team member strength profiles. Student groups were tasked with identifying the characters' primary strengths and workplace needs.

In week 7, the workshop continued in the didactic course where an 80-minute lecture provided students with tools to use when interacting in difficult team situations. Led by an expert in organizational communication, the session provided process-oriented communication models, including situational communication tools and group conflict resolutions models. The sessions for weeks 8 and 9 in the laboratory course were devoted to applying these tools to the two pharmacy scenarios that had been presented earlier in the semester. In the activity, student groups assessed elements of the conflict process, contributing factors, and team members' workplace needs. Groups then wrote a conflict management note and narrative to suggest ways to resolve the conflict based on situational communication tools and group conflict resolution models. Student groups then acted out the narrative the following week in the next laboratory session. This was followed by a short debriefing conducted by a laboratory facilitator to engage students in conversation on the situational communication tools they selected for each scenario.

In addition, a longitudinal element for CPD was included throughout the semester. ${ }^{13}$ First, students were tasked with writing a personal statement that required them to reflect on their top five strengths as well as their educational and professional goals. Students completed a midpoint and final peer evaluation in which they ranked their peers on specific performance characteristics and provided written feedback on what they perceived as each team member's top five strengths. The rubric used by students to evaluate each peer group member was developed by two of the authors modifying descriptors of professionalism defined by Hammer in 2000. ${ }^{17}$ The midpoint evaluation did not contribute to the students' grades but served to identify potential areas of improvement. Each student's final peer evaluation grade was calculated by averaging the scores from all of their peer evaluations and was worth $5 \%$ of the total course grade.

Students remained in their assigned groups for additional activities throughout the semester in the two linked classes, Introduction to Pharmacy Practice and Clinical Skills Lab I. Specifically, students completed approximately one low-stakes graded group activity in the lecture course each week and the group completed various laboratory activities for approximately two to three hours each week. Although these activities did not incorporate the described teamwork workshop components, the same student groups were maintained to ensure consistency in group learning. Beyond these two courses, students interacted with other students as part of different groups formed in other concurrent classes, depending on the structure and learning goals of the other classes.

\section{Data Analysis}

To evaluate the teamwork workshop, we used pre- and post-intervention surveys to assess changes in students' self-views of growth mindset and team communication. All students enrolled in the two courses were invited to participate in the surveys. Criteria for excluding a student from the study included refusal to provide consent, not completing both surveys, and having had to repeat the first-year of the curriculum. Students enrolled during the fall 2018 and fall 2019 semesters were the intervention group and completed the teamwork workshop and the pre- and post-workshop surveys. Because the teamwork workshop was not incorporated into the curriculum until fall 2018, students enrolled during the fall 2017 semester served as the control group as they had completed the same surveys as students in the intervention group but had not attended the teamwork workshop.

For both cohorts, the pre-workshop survey was completed within the first week of the semester and the post-workshop survey was completed during the last week. The surveys were administered using Qualtrics, and questions included those from the previously validated GMTC tool. ${ }^{16,18,19}$ To assess students' satisfaction with teamwork experiences, five additional questions were included in the survey that were modified (with permission) from questions used by Persky in 2012 to assess changes in pharmacy students' attitudes towards team learning. ${ }^{20}$ Additional questions in the pre-workshop survey assessed demographic information, including self-identification of personality, leadership strengths, and work experience. Changes within a cohort between the pre- and post-workshop surveys were analyzed using paired $t$ tests. Differences between the control and intervention groups were analyzed using independent samples 


\section{American Journal of Pharmaceutical Education 2021; 85 (5) Article 8269.}

$t$ tests. The Cohen's d formula was used to calculate the effect size for the overall GMTC scale as well as for the two subscales (ie, Growth Mindset and Team Communication subscales).

StrengthsFinder 2.0 provides students with their top five signature themes, often called top five strengths, out of the 34 possible signature themes. These top five strengths are determined based on the StrengthsFinder 2.0 algorithm to identify personalized results. To evaluate the results, the 34 Signature Themes assessed in the StrengthsFinder 2.0 were categorized into four leadership domains (executing, influencing, relationship building, and strategic thinking), as defined by Gallop. ${ }^{15}$ Each student's dominant domain, the occurrence of more than three Signature Themes within a single domain for an individual, was determined. This process to determine the dominant domain was previously defined by Janke and colleagues. ${ }^{21}$ The dominant domain themes were categorized into a total of five domains (above mentioned four leadership domains and one "no dominant" category for those without a dominant domain). The GMTC score was compared with the dominant domain using a oneway analysis of variance (ANOVA). Multiple linear regression was performed using the difference in GMTC score as a dependent variable. Independent variables for this analysis included gender, work experience, StrengthsFinder dominant domain results, and course grade. These were chosen based on the prior literature and available parameters. ${ }^{16}$

Focus groups were conducted at the end of the fall 2017 semester (control group) and fall 2018 semester (intervention group) in which students were asked to describe their teamwork experiences. Volunteer participants were recruited via an email announcement at the end of the semester. During the focus groups, participants responded verbally to eight open-ended questions, with four optional follow-up questions asked during audiorecorded sessions. Additionally, researcher facilitation and observational field notes were taken during the focus group sessions. Analysis was conducted on transcripts, with field notes providing context for coding memos. Top-level coding themes of attitude and action were selected based on previous validation of the GMTC Tool with each distinct comment coded first at both attitude and action, then inductive thematic analysis was performed with each top-level theme to determine unique subthemes. ${ }^{16,22-23}$ Attitudes were defined as the evaluation of pharmacy team experiences, while actions were defined as behaviors and communication used to explain the evaluation of those experiences. Responses were coded using NVivo, version 11 (QSR International). The study was approved by the High Point University Institutional Review Board.

\section{RESULTS}

Of the 74 students enrolled in fall 2017, 68 (91.9\%) were included in the control group. Of the 116 students enrolled in fall 2018 and fall 2019, 106 (91.4\%) were included in the intervention group. The demographics of the two cohorts were similar, except that more students in the intervention group self-identified as extroverts compared to the number in the control group (40.2\% vs $22.5 \%){ }^{16}$

When the difference between the pre- and post-survey scale was compared between the intervention and control groups, the cumulative GMTC scale showed a large effect size (Cohen's d of 0.94) between the groups. Based on the sum of the 14 growth mindset questions, the control group had a significant decrease in growth mindset between the pre- and post-survey vs the intervention group, which did not change significantly (Table 1). The standardized mean difference of an effect using the Cohen's d formula yielded a large effect size of 0.83 for the Growth Mindset subscale between the groups. Based on the sum of the scores on the 13 team communication questions, the intervention group had a significantly greater increase in team communication than the control group, which did not experience a significant change in team communication (Table 2). The Team Communication subscale yielded a moderate effect size of 0.63 as determined by Cohen's d. Overall, based on the sum of the five teamwork satisfaction questions, the intervention group had a significant increase in their satisfaction with teamwork experiences while the control group's satisfaction with teamwork experiences did not change significantly (Table 3).

The top five Signature Themes from StrengthsFinder 2.0 were Achiever, Harmony, Restorative, Futuristic, and Responsibility. The dominant domain distribution was: Executing ( $\mathrm{n}=23,23.6 \%)$, Relationship $(\mathrm{n}=21,19.8 \%)$, Strategic $(n=11,10.4 \%)$, Influencing $(n=5,4.7 \%)$, and No Dominant $(n=44,41.5 \%)$. For GMTC, the scores of students with Executing, Relationship, Strategic, and No Dominant as their dominant domains showed a trend toward improvement between the pre- and post-survey. This trend towards improvement was not seen in the scores of students whose dominant domain was Influencing (Figure 2).

A multiple linear regression to predict the difference in GMTC score based on gender, age, pharmacy-related work experience, number of Signature Themes belonging to each domain, and course grade did not result in any significant variable to predict the GMTC score.

Of the 68 students in the fall 2017 cohort, five (7.4\%) volunteered to participate in the one-hour focus group, and 48 distinct comments from the session were included in our 
American Journal of Pharmaceutical Education 2021; 85 (5) Article 8269.

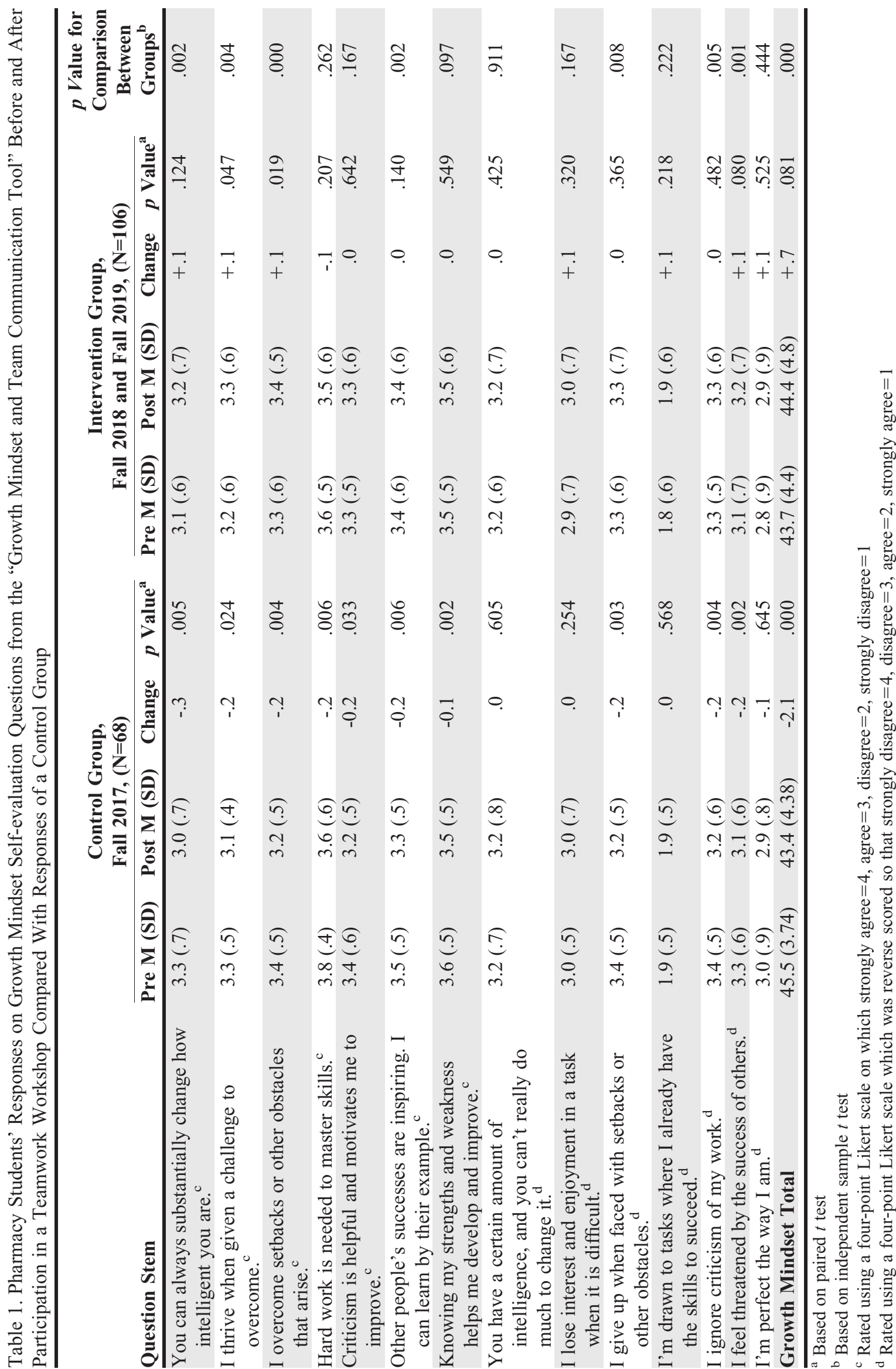


American Journal of Pharmaceutical Education 2021; 85 (5) Article 8269.

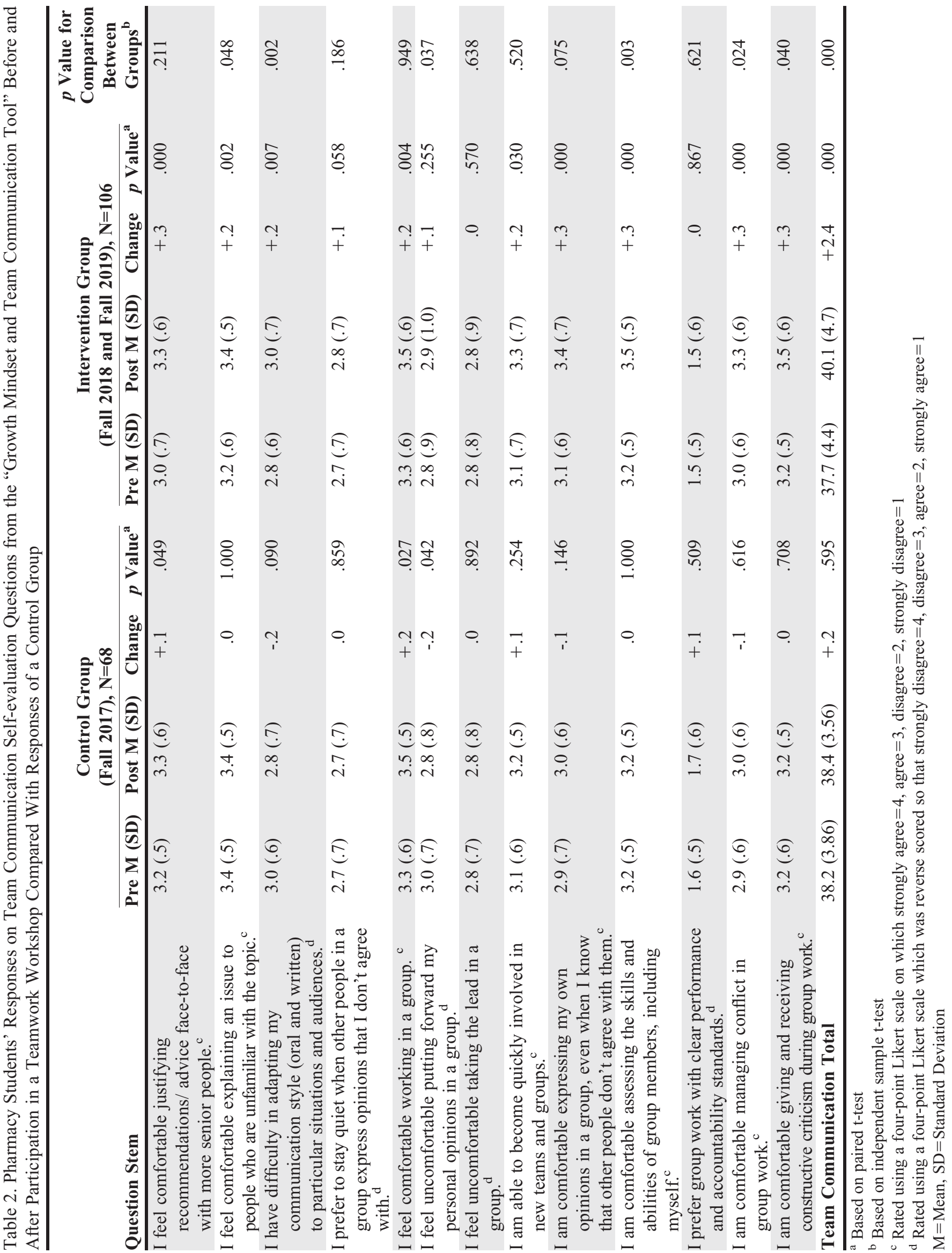




\section{American Journal of Pharmaceutical Education 2021; 85 (5) Article 8269.}

Table 3. Pharmacy Students' Responses on Satisfaction with Teamwork Experiences Questions Before and After Participation in a Teamwork Workshop Compared With Responses of a Control Group

\begin{tabular}{|c|c|c|c|c|c|c|c|c|c|}
\hline \multirow[b]{2}{*}{ Question Stem } & \multicolumn{4}{|c|}{$\begin{array}{l}\text { Control Group } \\
\text { (Fall 2017), N=68 }\end{array}$} & \multicolumn{4}{|c|}{$\begin{array}{c}\text { Intervention Group } \\
\text { (Fall } 2018 \text { and Fall 2019), N=106 }\end{array}$} & \multirow{2}{*}{$\begin{array}{c}p \text { Value for } \\
\text { Comparison } \\
\text { Between } \\
\text { Groups }^{b}\end{array}$} \\
\hline & $\begin{array}{c}\text { Pre M } \\
\text { (SD) }\end{array}$ & $\begin{array}{l}\text { Post M } \\
\text { (SD) }\end{array}$ & Change & $\begin{array}{c}p \\
\text { Value }^{a}\end{array}$ & $\begin{array}{l}\text { Pre M } \\
\text { (SD) }\end{array}$ & $\begin{array}{l}\text { Post M } \\
\text { (SD) }\end{array}$ & Change & $\begin{array}{c}p \\
\text { Value }^{\mathrm{a}}\end{array}$ & \\
\hline $\begin{array}{l}\text { I have found working as } \\
\text { part of a team in my } \\
\text { classes to be a valuable } \\
\text { experience. }^{\text {c }}\end{array}$ & $3.3(.6)$ & $3.2(.6)$ & -.1 & .373 & $3.2(.6)$ & $3.3(.7)$ & +.0 & .649 & .324 \\
\hline $\begin{array}{l}\text { In most teams I have been } \\
\text { on, the team has worked } \\
\text { well together. }\end{array}$ & $3.0(.6)$ & $3.2(.5)$ & +.2 & .086 & $3.1(.6)$ & $3.3(.7)$ & +.2 & .010 & .879 \\
\hline $\begin{array}{l}\text { In most of the teams I have } \\
\text { been on, I felt the other } \\
\text { team members } \\
\text { respected me. }\end{array}$ & $3.3(.5)$ & $3.3(.5)$ & .0 & 1.000 & $3.2(.6)$ & $3.4(.6)$ & +.2 & .024 & .113 \\
\hline $\begin{array}{l}\text { In most of the teams I have } \\
\text { been on, I generally } \\
\text { contribute more than } \\
\text { other team members. }{ }^{\mathrm{c}}\end{array}$ & $2.9(.7)$ & $2.7(.7)$ & -.3 & .001 & $2.9(.6)$ & $2.8(.7)$ & -.2 & .032 & .229 \\
\hline $\begin{array}{l}\text { I have found that working } \\
\text { with a team helps me } \\
\text { develop skills in } \\
\text { working with others. }^{\mathrm{c}}\end{array}$ & $3.4(.5)$ & $3.2(.5)$ & -.2 & .006 & $3.4(.6)$ & $3.4(.6)$ & .0 & .863 & .022 \\
\hline Team Satisfaction Total & $15.9(1.8)$ & $15.6(1.7)$ & -.4 & .068 & $15.8(2.0)$ & $16.1(2.1)$ & +.2 & .197 & .026 \\
\hline
\end{tabular}

${ }^{a}$ Based on paired t-test

${ }^{\mathrm{b}}$ Based on independent sample t-test

${ }^{c}$ Scale 1-4 Likert: Strongly Agree $=4$, Agree $=3$, Disagree $=2$, Strongly Disagree $=1$

$\mathrm{M}=$ Mean, $\mathrm{SD}=$ Standard Deviation

analysis. Of the 57 students in the fall 2018 cohort, three $(5.3 \%)$ volunteered to participate in the focus group and 70 distinct comments were included in our analysis. Although which team a student had been on during the workshop was not considered when recruiting participants for the focus groups, the volunteers in each focus group included students from different teams with no participating students from the same group. Students' attitudes expressed in the
118 total distinct comments were categorized as positive, mixed, or negative. These results revealed a difference between the control and intervention groups in that the responses of students in the intervention group were more balanced, with positive and mixed attitudes expressed, compared to the comments of students in the control group, which were generally more positive (Table 4). Corresponding action codes revealed that students found value in
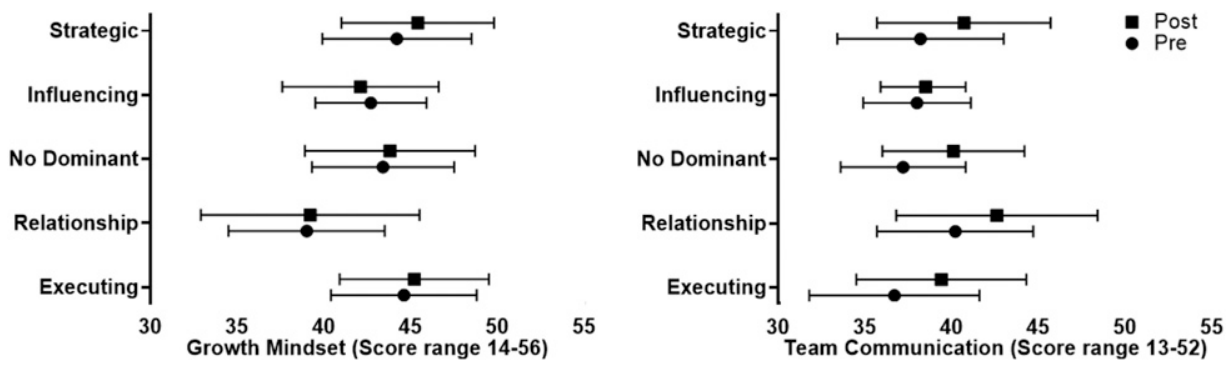

Figure 2. Growth Mindset (2A) and Team Communication (2B) Score Trend in Relation to Dominant Domain Category for the Intervention Group. Of the 106 Participants, Students were Categorized into Each Dominant Domain Resulting in: Executing $(\mathrm{n}=23,23.6 \%)$, Relationship $(\mathrm{n}=21,19.8 \%)$, Strategic $(\mathrm{n}=11,10.4 \%)$, Influencing $(\mathrm{n}=5,4.7 \%)$, and No Dominant $(\mathrm{n}=44$, 41.5\%). Changes in Growth Mindset and Team Communication Between the Pre- and Post-Surveys are Shown. 


\section{American Journal of Pharmaceutical Education 2021; 85 (5) Article 8269.}

Table 4. Focus Group Qualitative Results for Intervention Group Participants After Participation in a Teamwork Workshop ( $\mathrm{n}=3$ Students in Intervnetion Focus Group) Compared to Control Group Participants ( $\mathrm{n}=5$ Students in Control Focus Group)

\begin{tabular}{|c|c|c|c|c|c|c|}
\hline \multirow[b]{2}{*}{ Categories and Subcategories } & \multicolumn{2}{|c|}{$\begin{array}{l}\text { Control Focus Group } \\
\text { (Fall 2017) } \mathrm{n}=48 \\
\text { Distinct Comments }\end{array}$} & \multicolumn{2}{|c|}{$\begin{array}{c}\text { Group } \\
\text { (Fall 2018) } \mathrm{n}=\mathbf{7 0} \\
\text { Distinct Comments }\end{array}$} & \multicolumn{2}{|c|}{$\begin{array}{c}\text { Total } \\
\mathbf{n}=\mathbf{1 1 8} \\
\text { Distinct Comments }^{\mathrm{a}}\end{array}$} \\
\hline & $\mathbf{n}$ & $\%$ & n & $\%$ & $\mathbf{n}$ & $\%$ \\
\hline \multicolumn{7}{|c|}{ Attitudes (defined as evaluation of pharmacy team experience) } \\
\hline Positive & 42 & 87.5 & 38 & 54.3 & 80 & 67.8 \\
\hline \multicolumn{7}{|c|}{ Actions (defined as behavior and communication used to explain the evaluation) } \\
\hline $\begin{array}{l}\text { Shared resources (pooling resources }- \text { like } \\
\text { labor and knowledge }- \text { through } \\
\text { collaboration) }\end{array}$ & 22 & 45.8 & 19 & 27.2 & 41 & 34.8 \\
\hline Sample comment & \multicolumn{6}{|c|}{$\begin{array}{l}\text { When we work in a group, not everybody's gonna be good at everything. So } \\
\text { that might be your strong point but then there might be someone in your } \\
\text { group, whatever your weak point is might be their strong point. You guys } \\
\text { can work together to come up with the best outcome. }\end{array}$} \\
\hline $\begin{array}{l}\text { Diverse perspectives (bringing unique } \\
\text { perspectives, knowledge, or experience) }\end{array}$ & 11 & 22.9 & 26 & 37.1 & 37 & 31.4 \\
\hline Sample comment & \multicolumn{6}{|c|}{$\begin{array}{l}\text { Our group, we have completely different backgrounds, but we are really good } \\
\text { for each other, help each other, and learn a lot from each other. Now, we sit } \\
\text { down, look at the problem, and are like we got this. We work well together. } \\
\text { It definitely has its benefits. }\end{array}$} \\
\hline $\begin{array}{l}\text { Professional preparation (gaining skills and } \\
\text { knowledge for a successful job/career) }\end{array}$ & 8 & 16.7 & 12 & 17.1 & 20 & 16.9 \\
\hline Sample comment & \multicolumn{6}{|c|}{$\begin{array}{l}\text { I've been placed in groups here (in school) where I've never talked to my } \\
\text { group members. But in those groups, we're able to build that connection } \\
\text { and grow and use that as a key foundation in the real world. When you're } \\
\text { working for a company or whatever, you're being placed in different } \\
\text { groups, you have different group assignments, and you need to know how to } \\
\text { work together and this (school) is just practice. }\end{array}$} \\
\hline Sample comment & \multicolumn{6}{|c|}{$\begin{array}{l}\text { I like groups. I want to work with everyone, get to know everyone. We } \\
\text { migrate to the people we know, and we are stressed. I mean good stress, but } \\
\text { it is comforting making friends. My (class) group, we get together on Friday } \\
\text { nights for - um - adult beverages and play games to relax and decompress } \\
\text { because this (school) is stressful. }\end{array}$} \\
\hline
\end{tabular}

${ }^{a}$ Each of the $n=118$ distinct comments were coded into the two top-level codes of attitude and action

team communication and collaboration, noting that team experiences allowed them to share resources, learn from diverse perspectives, prepare for their future job/career, and build supportive relationships. These findings regarding students preparing for their future profession and building supportive relationships were similar between the control and intervention groups. However, the control and intervention groups diverged in sharing resources vs learning from diverse perspectives. The control group spoke more about shared resources while the intervention group's discussion was more focused on learning from diverse perspectives. These differences extended to the content of students' comments, with those in the control group valuing shared resources more for the purpose of collaborating to achieve a positive outcome vs those in the intervention group valuing the experience of learning from diverse perspectives, knowledge, or experience through the teamwork process (Table 4).

\section{DISCUSSION}

This study assessed the impact of a multi-week workshop on team communication for PharmD students 


\section{American Journal of Pharmaceutical Education 2021; 85 (5) Article 8269.}

using the validated GMTC tool. The intervention group showed a significant increase in both Growth Mindset $(+0.7, p<.05)$ and Team Communication $(+2.4, p<.05)$, suggesting the workshop had a positive impact on students' attitudes related to teamwork. This is consistent with findings from a previous study by Hagemeier and colleagues which found that pharmacy students completing an interprofessional communication course resulted in improved students' self-efficacy beliefs. ${ }^{24}$ Although the quantitative increase in the subscale values was small, the effect size findings support that the workshop provided useful training for pharmacy students. Thus, early interventions aiming to improve pharmacy students' self-awareness and self-evaluation skills in the context of direct instruction on team conflict models may be beneficial.

The GMTC tool captured data on two subscales: Growth Mindset and Team Communication. The growth mindset score showed a significant increase in the intervention group and a nonsignificant decrease in the control group. Overall, this resulted in a significant difference between the two groups showing again that the intervention may have contributed to a small improvement in growth mindset. This is the first study in pharmacy education to evaluate pre-post change in students' growth mindset. In pharmacy students, the transition into a professional program with high expectations could result in a decrease in growth mindset. This study explored this critical transition to professional school in the first semester. Notably the magnitude of change was larger in the team communication subscale. The growth mindset subscale may be less sensitive and reactive to external intervention, while the team communication subscale may more directly capture changes from the educational intervention that encourages an integrative teamwork environment.

Within the team communication subscale, two reverse scored items had no change: "I feel uncomfortable taking the lead in a group" and "I prefer group work with clear performance and accountability standards." Leadership and accountability skills were not emphasized in this workshop. Thus, this may represent a skill that could be emphasized in future iterations of the teamwork workshop. Clear performance and accountability standards is an interesting item because practice standards are increasingly common and may be essential to quality care. However, in other instances, standards may limit team growth, flexibility, and innovation. Accountability standards represent emerging professional teamwork concepts that were not discussed in this introductory teamwork workshop.

The qualitative results reflected overall positive views of team communication and collaboration, which was contextualized by discussions of advantages and challenges faced during the teamwork process and primarily positive outcomes. Comparison between the four action subthemes for the control and intervention groups suggest the intervention group may have benefited from the workshop. The control group's positive evaluation included fewer comments related to process or collaborative solutions to teamwork challenges. In contrast, the intervention group demonstrated self-awareness, reflection on the process of teamwork, and openness to adapting and learning to overcome challenges. The intervention group resulted in more balance between positive and mixed attitudes as their comments suggested they were prepared, potentially by the intervention, to maximize the positive advantages and overcome negative challenges by managing the teamwork process to enhance learning, achieve positive outcomes, and prepare for the future through transferable teamwork and communication skills. The control group's positive comments regarding actions may suggest less awareness and critique of the team process compared to the process assessment expressed by the intervention group which they attributed to the skills practiced and lessons learned during the intervention's workshop series. Both the control and intervention groups discussed concern for collaborating within high-stakes assignments, which suggests that future inclusion of accountability standards content could help reinforce students' responsibility in roles and tasks as the collaborative process is used in more difficult assignments.

The satisfaction with teamwork experiences as assessed by five questions in the survey provided a general positive view of teamwork experiences from the student perspective. Interestingly, both the control and intervention groups had many students in agreement with the question assessing contribution: "In most of the teams that I have been on, I generally contribute more than other team members." This could represent a bias of overestimating one's abilities and an opportunity to communicate expectations of group members in future groupwork. A major limitation of these survey questions is that the tool included general questions related to teamwork satisfaction without particular focus on this workshop or the assigned team used in these two particular classes. Thus, past experiences and current experiences on different teams may have impacted the results related to these specific questions.

Using the results from StrengthsFinder 2.0 for the intervention cohort, within each dominant domain category, the growth mindset subscale did not change before and after the intervention; however, the team communication subscale showed significant improvement in all 


\section{American Journal of Pharmaceutical Education 2021; 85 (5) Article 8269.}

dominant domains, except Influencing (Figure 2). According to Gallup's CliftonStrengths assessment, people with Influencing dominant domain share expertise in communication by "taking charge, speaking up and making sure others are heard. " ${ }^{15}$ It is interesting to see that people who perceive themselves as "communicators" (ie, Influencing) may be less likely to have an impactful change in team communication subscale; however, this finding is limited by a small number of students with Influencing as their dominant domain. When compared with findings from the study conducted by Janke and colleagues, our pharmacy students had similar trends in Signature Themes compared to those found in pharmacy schools located in the Midwest. ${ }^{21}$

Limitations of this study include a single institution and a single-profession design. Although the single-professional design was planned so students could learn necessary teamwork skills before entering IPE experiences, it may be valuable to conduct early teamwork training among multiple health care disciplines. The study is also limited by a low participation rate and number of focus groups. ${ }^{25}$ Another limitation is the teamwork satisfaction questions which are not written in a way that focuses the questions on student perceptions for the specific team that was utilized in these two courses. Furthermore, this study assessed students' views of their skills related to teamwork communication without including objective assessment of students' skills by faculty. Although teamwork skills are difficult for faculty to evaluate when not present for individual team meetings, future work may consider objective measurements of individual students' team communication skills.

An additional limitation is the nature of teamwork as a complex skill. Teamwork requires the development of interpersonal and conflict management skills which often takes years of experience to develop. Although this teamwork workshop and concurrent coursework provided students with the opportunity to spend a considerable amount of time working in their teams, there is always the possibility that teams were in different stages of team formation, and that this impacted the pre- and post-survey results in various ways. Additionally, the multi-week workshop held during one semester may not have been a sufficient amount of time for students to make lasting affective domain changes related to teamwork or growth mindset. Furthermore, an additional limitation is the difficulty in using a psychometric test, such as the GMTC, as there is not yet a threshold established in the literature defining the meaningful difference needed to demonstrate effect. The minimal clinically important difference (MCID) of GMTC score improvement of 6 points was calculated based on a large effect size of 0.8 using Cohen's d formula. Both the growth mindset subscale and the team communication subscale were calculated to have an MCID of 3 points to reflect a large effect size. Our findings did not achieve score improvement greater than 6 points to meet the MCID, however future studies involving a larger sample size could be conducted to re-calculate the MCID. Nonetheless, based on the trend of improved teamwork communication, this study demonstrates that a teamwork workshop held early in the pharmacy curriculum has the potential to contribute to student learning of teamwork concepts. This exploration of early formative professional teamwork experiences and change over time expands our knowledge of strengths and teamwork across the pharmacy curriculum. ${ }^{12,14}$

\section{CONCLUSION}

A teamwork workshop focused on maximizing strengths and resolving conflict resulted in a small improvement in first-year pharmacy students views of team communication abilities. An early workshop may provide pharmacy students with the necessary teamwork and conflict management skills needed for academic and professional success. Future work should focus on longitudinal measurement of pharmacy students' self-views to determine the long-term impact of teamwork training interventions and if such interventions result in students' success on future health care teams.

\section{ACKNOWLEDGMENTS}

The authors acknowledge the American Association of Colleges of Pharmacy Scholarship of Teaching and Learning (SoTL) Grant Program and the High Point University Growth Mindset SoTL Grant Program which both provided funding for the completion of this project.

\section{REFERENCES}

1. Baker DP, Day R, Salas E. Teamwork as an essential component of high-reliability organizations. Health Serv Res. 2006;41(4 Pt 2): 1576-1598. doi:10.1111/j.1475-6773.2006.00566.x

2. Rosen MA, DiazGranados D, Dietz AS, et al. Teamwork in healthcare: key discoveries enabling safer, high-quality care. Am Psychol. 2018;73(4):433-450. doi: 10.1037/amp0000298

3. Accreditation Council for Pharmacy Education. Accreditation standards and key elements for the professional program in pharmacy leading to the doctor of pharmacy degree ("Standards 2016"). https:// www.acpe-accredit.org/pdf/Standards2016FINAL.pdf. Accessed April 27, 2021.

4. Page RL, Hume AL, Trujillo JM, et al. Interprofessional education: principles and application. a framework for clinical pharmacy. Pharmacotherapy; 2009;29(3):145e-164e. DOI: 10.1592/ phco.29.7.879

5. Lockeman KS, Lanning SK, Dow AW, et al. Outcomes of introducing early learners to interprofessional competencies in a 


\section{American Journal of Pharmaceutical Education 2021; 85 (5) Article 8269.}

classroom setting. Teaching Learn Med. 2017;29(4):433-443. DOI: 10.1080/10401334.2017.1296361

6. Fox L, Onders R, Hermansen-Kobulnicky CJ, et al. Teaching interprofessional teamwork skills to healthprofessional students: a scoping review. J Interprof Care. 2018;32(2):127-135. DOI: 10.1080/13561820.2017.1399868.

7. Baker DP, Day R and Salas E. Teamwork as an essential component of high-reliability organizations. Health Serv Res. 2006; 41(4 Pt 2):1576-98. DOI: 10.1111/j.1475-6773.2006.00566.x 8. Fete MG, Haight RC, Clapp P, McCollum M. Peer evaluation instrument development, administration, and assessment in a teambased learning curriculum. Am J Pharm Educ. 2017;81(4):68. DOI: 10.5688/ajpe 81468

9. Dweck CS. Self-Theories: Their Role in Motivation, Personality, and Development. Florence, KY: Psychology Press, Taylor and Francis Group; 2000. https://eric.ed.gov/?id=ED448913. Accessed April 27, 2021.

10. Blackwell LS, Trzesniewski KH, Dweck CS. Implicit theories of intelligence predict achievement across an adolescent transition: a longitudinal study and an intervention. Child Dev. 2007;78(1): 246-263. DOI: 10.1111/j.1467-8624.2007.00995.x

11. Good C, Rattan A, Dweck CS. Why do women opt out? Sense of belonging and women's representation in mathematics. J Pers Soc Psychol. 2012;102(4):700. DOI: 10.1037/a0026659

12. Persky AM, Henry T, Campbell A. An exploratory analysis of personality, attitudes, and study skills on the learning curve within a team-based learning environment. Am J Pharm Edu. 2015;79(2):20. DOI: 10.5688/ajpe79220

13. Weaver SJ, Dy SM, Rosen MA. Team-training in healthcare: a narrative synthesis of the literature. BMJ Qual Saf. 2014;23(5):

359-372. DOI: 10.1136/bmjqs-2013-001848

14. Janke KK, Traynor AP, Sorensen TD. Refinement of strengths instruction in a pharmacy curriculum over eight years. Am J Pharm Edu. 2011;75(3):45. DOI: 10.5688/ajpe75345
15. Rath T. Strengthsfinder 2.0. Simon and Schuster; 2007. 16. Cooper J, Lee S, Jeter E, Bradley CL. Psychometric validation of a tool to measure self-views of growth mindset and team communication skills. J Am Pharm Assoc. 2020; S1544-3191(20) 30199-0. DOI:10.1016/j.japh.2020.04.012

17. Hammer DP. Professional attitudes and behaviors: the "A's and B's" of professionalism. Am J Pharm Educ 2000;64(winter):455-464. 18. Dweck CS, Chiu CY, Hong YY. Implicit theories and their role in judgments and reactions: a world from two perspectives. Psychol Inq. 1995;6(4):267-285.

19. Pollard KC, Miers ME, Gilchrist M. Collaborative learning for collaborative working? Initial findings from a longitudinal study of health and social care students. Health Soc Care Community. 2004; 12(4):346-358. DOI: 10.1111/j.1365-2524.2004.00504.x

20. Persky AM. The impact of team-based learning on a foundational pharmacokinetics course. Am J Pharm Educ 2012;76(2):31. DOI: 10.5688/ajpe76231

21. Janke KK, Farris KB, Kelley KA, et al. StrengthsFinder signature themes of talent in doctor of pharmacy students in five Midwestern pharmacy schools. Am J Pharm Educ. 2015;79(4):49. DOI: 10.5688/ ajpe 79449

22. Saldana J. The Coding Manual for Qualitative Researchers. Thousand Oaks, CA: Sage; 2015.

23. Tracy SJ. Qualitative Research Methods: Collecting Evidence, Crafting Analysis, Communicating Impact. Chichester, West Sussex, UK: Wiley-Blackwell; 2013.

24. Hagemeier NE, Hess R, Hagen KS, Sorah EL. Impact of an interprofessional communication course on nursing, medical, and pharmacy students' communication skill self-efficacy beliefs. Am J Pharm Educ. 2014;78(10):186. DOI: 10.5688/ajpe7810186.

25. Guest G, Namey E, McKenna K. How many focus groups are enough? Building an evidence base for nonprobability sample sizes. Field Methods. 2017;29(1):3-22. DOI: 10.1177/ $1525822 \mathrm{X} 16639015$ 